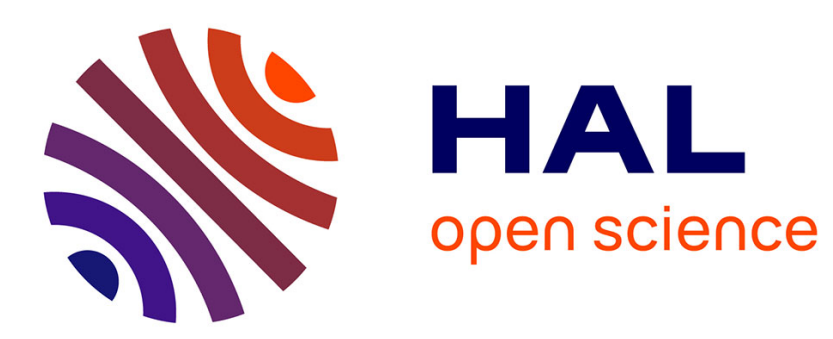

\title{
Maximum reachable torque, power and speed for five-phase SPM machine with low armature reaction
}

Franck Scuiller, Hussein Zahr, Eric Semail

\section{To cite this version:}

Franck Scuiller, Hussein Zahr, Eric Semail. Maximum reachable torque, power and speed for fivephase SPM machine with low armature reaction. IEEE Transactions on Energy Conversion, 2016, 99, pp.1-10. 10.1109/TEC.2016.2542581 . hal-01294969

\section{HAL Id: hal-01294969 \\ https://hal.science/hal-01294969}

Submitted on 30 Mar 2016

HAL is a multi-disciplinary open access archive for the deposit and dissemination of scientific research documents, whether they are published or not. The documents may come from teaching and research institutions in France or abroad, or from public or private research centers.
L'archive ouverte pluridisciplinaire HAL, est destinée au dépôt et à la diffusion de documents scientifiques de niveau recherche, publiés ou non, émanant des établissements d'enseignement et de recherche français ou étrangers, des laboratoires publics ou privés. 


\title{
Maximum reachable torque, power and speed for five-phase SPM machine with low armature reaction
}

\author{
Franck Scuiller, Member, IEEE, Hussein Zahr, Student Member, IEEE, and Eric Semail, Member, IEEE
}

\begin{abstract}
In this paper, the study of the torque and power versus speed characteristics for a family of five-phase Surfacemounted Permanent Magnet (SPM) machine is carried out. With considering hypotheses (linear magnetic modeling, only first and third harmonic terms in the back-emf and current spectrums), an optimization problem that aims to maximize the torque for given maximum peak voltage and RMS current is formulated: the optimal torque sharing among the two virtual machines (the two dq-axis subspaces) that represent the real five-phase machine is thus calculated for any mechanical speed. For an inverter and a DC voltage sized with only considering the first harmonic of backemf and current, the problem is solved with changing the virtual machine back-emfs and inductances ratios. With the introduction of the maximum torque/speed point, maximum power/speed point and maximum reachable speed, it can be shown that, if the inductance ratio is large enough, for given Volt-Ampere rating, the machine can produce higher torque without reducing its speed range thus meaning that the capability of the inverter to work is improved with the use of the third harmonic. This property is all the truer as the base armature reaction is large. A particular five-phase machine is sized and numerically analyzed to check this property.
\end{abstract}

Index Terms-Five-phase machine, Surface-mounted PM machine, Speed range, Flux weakening.

\begin{tabular}{ll} 
& \multicolumn{1}{c}{ NomENCLATURE } \\
FW & Flux Weakening \\
MM & Main Machine (1st harmonic) \\
SM & Secondary Machine (3rd harmonic) \\
p.u. & Per Unit \\
$p$ & Pole pair number \\
$R$ & Armature resistance \\
$\Psi_{1}, \Psi_{3}$ & MM and SM flux \\
$L_{1}, L_{3}$ & MM and SM cyclic inductances \\
$\theta_{1}, \theta_{3}$ & MM and SM back-emf to current angles \\
$I_{1}, I_{3}$ & MM and SM currents \\
$\Omega, \omega$ & Mechanical and electrical speed (rad/s) \\
$V_{b}, I_{b}$ & Base RMS voltage and current \\
$\Omega_{b}, T_{b}$ & Base speed and torque \\
$r$ & p.u. armature resistance \\
$e_{1}, x_{1}$ & p.u. MM back-emf and inductance \\
$e_{3}, x_{3}$ & p.u. SM back-emf and inductance \\
$y, t$ & p.u. speed and torque \\
$p_{e m}$ & p.u. power \\
$\left(y_{t}, t_{m}\right)$ & p.u. (speed, torque) max torque point \\
$\left(y_{p}, p_{e m, m}\right)$ & p.u. (speed, torque) max power point \\
$y_{m}$ & p.u. max reachable speed
\end{tabular}

F. Scuiller is with the Naval Academy Research Institute, BCRM Brest - EN/GEP CC 600 - 29240 BREST Cedex 9 - FRANCE (e-mail: franck.scuiller@ecole-navale.fr)

H. Zahr and E. Semail are with the Laboratory of Electrical Engineering and Power Electronics of Lille (L2EP), Arts et Métiers ParisTech, LILLE 59043 - FRANCE (e-mail: \{hussein.zahr,eric.semail\}@ensam.eu)

\section{INTRODUCTION}

$\mathbf{I}^{\mathrm{N}}$ $\mathrm{N}$ electric vehicle or marine propulsion applications, high power density and fault tolerant capability are commonly required for the machine drive. This context favours the use of multi-phase PM machines. Furthermore, a wide speed range capability is also often wanted thus making the machine operating in the flux weakening region in order to take into account the limited DC bus voltage [1].

Numerous papers deal with the FW operation of three-phase PM machines fed by voltage source inverter. For instance, in [2], [3], with considering classical dq-circuit model of threephase PM machine (with or without saliency), the authors analytically determine the torque/speed characteristic for the whole speed range. In [4], the authors focus on the winding design influence on the FW ability. A similar analysis is undertaken in [5] for Surface-mounted PM machines (SPM).

On the contrary, few papers address the FW operation of multi-phase PM machines. This is mainly because five-phase drives are not used to the same extent as their three-phase counterparts. Another justification probably results from the fact that a multi-phase machine behaves as several dq-circuit machines (or dq subspaces), thus making difficult the analytical computation of the currents in FW mode. It is all the more a problem that, in contrary to the wye-coupled three-phase machines, the third harmonic components of magnetomotive force and electromotive force have a great influence on the performance in flux-weakening region. In [6], [7], the impacts of third harmonic current injection and of third harmonic electromotive force value are studied in a three-phase PM machine with a fractional-slot open-winding. Different nonlinear control strategies depending on the working point are deduced in order to optimize the use of the DC-bus voltage with constraint of RMS current [8]. For five-phase machine the same kind of problem appears even with a star coupling but with supplementary degree of freedom. Therefore it can be considered interesting to provide for five-phase PM machines elements of analysis showing the impact of spatial third harmonic component on the potentialities of the flux weakening. Currently, flux-weakening studies on five-phase machines always consider a particular machine and search to optimize either the machine or the control for working in flux weakening operation. In addition the optimization is done on a particular speed working point [9]-[11], which restricts highly the applicability of the results to other multi-phase machines. To study the FW ability of multi-phase machine is equivalent to analyze how to improve the DC bus utilization. This problem is analyzed in [12] where an analytical approach is detailed to determine the boundaries of the linear modulation 
region for multi-phase inverter. However this study is restricted to the converter side thus meaning that the effects of the multiphase machine back-emf and inductances are not explicitly examined. Nevertheless the effectiveness of this approach is demonstrated in [13], [14] where it is applied to a seven-phase induction machine with FW capacity. It should be noted that, for three-phase PM machine, the per unit system used in [2] gives results naturally applicable for any machine, which is particularly useful for the designer.

Actually, in order to study the FW mode of multi-phase machine, a numerical approach is necessary: an optimization problem has to be formulated and solved to determine the currents sharing among the dq subspaces at a given speed for a given DC voltage [1], [15], [16]. For given optimization problem and numerical method, the results will depend on the way to represent the machine and the inverter. The more accurate approach consists in modeling the machine with Finite Element Analysis and the inverter with time differential equations to account the commutations. Such an approach is hard to implement and computionally time-consuming. Another possibility consists in using the equivalent multi dqcircuit model for the multi-phase SPM machine [17] and an average model for the inverter. The steady-state torque/speed characteristic can thereby be estimated with considering a quite reduced number of parameters, which provides more applicable results for the designer. In practical terms, with the proposed approach, the designer can predict the change in the Torque/Speed characteristic when acting on the winding distribution and the magnet layer design (bearing in mind that the impacts on the torque quality is analysed in [18] for example).

Therefore the paper aims to provide, for a family of fivephase SPM machines, elements showing the impact of spatial third harmonic components on the potentialities of the drive to operate in the FW region: external Torque/Speed and Power/Speed characteristics are chosen to achieve this analysis. As the spatial third harmonic components result from the PM implementation [18], [19] but also from the winding [20], the chosen macroscopic elements for the study are the inductances and the electromotive forces. The paper is divided into four parts. In the first part, the multimachine modeling of the five-phase SPM machine is introduced and the per unit system used to perform the analysis is described. In the second part, the numerical optimization procedure to estimate the maximum torque and power of a five-phase machine at a given speed is detailed. In addition, the particular speed points in the torque and power versus speed characteristics are defined. In the third part, the influence of the machine parameters on the torque, power and speed range for given Volt-Ampere rating is assessed. The last part is dedicated to the numerical simulation of a five-phase machine in order to show how the results given in the previous parts can be used at the design step.

\section{FIVE-PHASE MACHINE MODELING}

\section{A. Hypotheses}

If the magnetic saturations and the demagnetization issue are not considered, it can be shown that a star-connected five- phase SPM machine behaves as two two-phase virtual machines that are magnetically independent but electrically and mechanically coupled [21]. Furthermore, as the rotor saliency can be neglected with SPM machines, the space harmonics are distributed among the two virtual machines: the virtual machine sensitive to the fundamental is called Main Machine (MM) whereas the other sensitive to the third harmonic is called Secondary Machine (SM). Actually the virtual machine is a physical reading of the mathematical subspace build on the linear application that describes the phase-to-phase magnetic couplings: this two-dimension subspace is usually represented with $\alpha \beta$-axis circuit in stationary frame or with $d q$-axis circuit in rotating frame. As there is no saliency effect, no distinction has to be made between $\mathrm{d}$-axis and q-axis inductance. Additional hypotheses will be taken:

- the machine has a low armature reaction which implies that the speed range under FW control is finite [2]

- only 1 st and 3rd space and time harmonics are considered thus meaning that each virtual machine owns a sinusoidal back-emf and is supplied with sinusoidal current (switching effects are disregarded).

Regarding the last hypothesis, it should be noted that, in [22] where the FW capacities of 3-phase PM traction motors are studied, from design and experimental considerations, the authors report that sinusoidal back-EMF waveform demonstrates high efficiency over a wider speed range.

\section{B. Base point choice}

As for a three-phase machine, it is considered that the base quantities of the five-phase machine are obtained with a perfect sinusoidal supply of the Main Machine because the Main Machine usually determines the real machine pole pair number. Below the base speed, the machine is controlled according to Maximum Torque Per Ampere (MTPA) strategy. Fig. 1 shows the vectorial diagram corresponding to the base point where base current $I_{b}$, base electrical speed $\omega_{b}$ and base voltage $V_{b}$ are defined. The base voltage can easily be calculated by considering the vectorial diagram:

$$
V_{b}=\sqrt{\left(\Psi_{1} \omega_{b}+R I_{b}\right)^{2}+\left(L_{1} \omega_{b} I_{b}\right)^{2}}
$$

Per unit armature resistance, inductance and back-emf are classically defined:

$$
\left\{\begin{array}{l}
r=\frac{R I_{b}}{V_{b}} \\
x_{1}=\frac{L_{1} \omega_{b} I_{b}}{V_{b}} \\
e_{1}=\frac{\Psi_{1} \omega_{b}}{V_{b}}
\end{array}\right.
$$

Low armature reaction hypothesis means that $x_{1}$ is lower than 0.707 [2] (if armature resistance is neglected). The per unit speed (electrical or mechanical) can be defined:

$$
y=\frac{\omega}{\omega_{b}}=\frac{\Omega}{\Omega_{b}}
$$


Per unit inductance $x_{3}$ and back-emf $e_{3}$ for the Secondary Machine are now introduced:

$$
\left\{\begin{aligned}
x_{3} & =\frac{L_{3} \omega_{b} I_{b}}{V_{b}} \\
e_{3} & =\frac{3 \Psi_{3} \omega_{b}}{V_{b}}
\end{aligned}\right.
$$

According to the base point definition, the sinus control of the Main Machine enables the five-phase machine to produce the base torque $T_{b}$ as long as the mechanical speed is lower than the base mechanical speed $\Omega_{b}$. The base torque $T_{b}$ can then be calculated according to the MM parameters:

$$
T_{b}=5 p \Psi_{1} I_{b}
$$

The base power is simply defined as the product of base voltage with base current:

$$
P_{b}=5 V_{b} I_{b}
$$

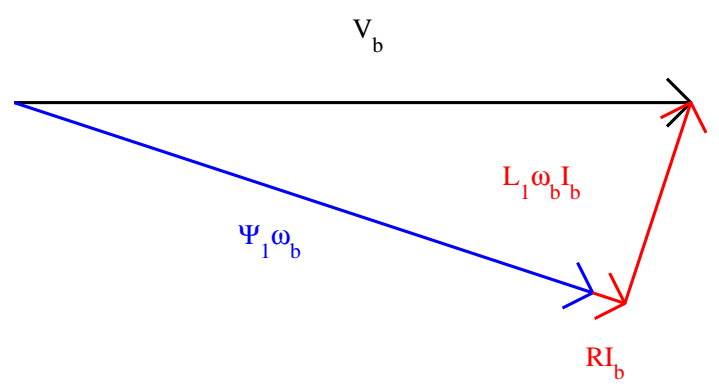

Fig. 1. Voltage vectorial diagram for the base point

\section{Phase voltage equations}

If only first time and space harmonics are considered for the Main Machine, the Main Machine contribution to one of the five real phase voltages can be calculated. When using the per unit system previously described, the equation is (where $\theta_{e}$ denotes the electrical angle):

$$
\begin{aligned}
v_{1}\left(\theta_{e}\right)= & y e_{1} \sin \left(\theta_{e}\right) \\
& +r i_{1} \sin \left(\theta_{e}+\theta_{1}\right) \\
& +y x_{1} i_{1} \sin \left(\theta_{e}+\theta_{1}+\frac{\pi}{2}\right)
\end{aligned}
$$

The SM contribution to the phase voltage is simply obtained by replacing subscribe 1 by subscribe 3 in (7) and changing the pole pair number. In the per unit system, the following expression is obtained:

$$
\begin{aligned}
v_{3}\left(\theta_{e}\right)= & y e_{3} \sin \left(3 \theta_{e}\right) \\
& +\operatorname{sgn}\left(e_{3}\right) r i_{3} \sin \left(3 \theta_{e}+\theta_{3}\right) \\
& +\operatorname{sgn}\left(e_{3}\right) 3 y x_{3} i_{3} \sin \left(3 \theta_{e}+\theta_{3}+\frac{\pi}{2}\right)
\end{aligned}
$$

In the previous equation, sgn is the sign function. One must bear in mind that MM and SM are mechanically coupled. This property implies that MM d-axis and SM d-axis are always superimposed but not necessarily in the same direction: $e_{3}$ (i.e. $\Psi_{3}$ ) and $e_{1}$ (i.e. $\Psi_{1}$ ) can be in phase or in opposition. The chosen sinus description of the voltage allows to simply take into account the two possibilities by assuming that $e_{1}$ is a positive number and $e_{3}$ is a signed number: if $e_{3}$ is positive, $e_{3}$ and $e_{1}$ are in phase; else, $e_{3}$ and $e_{1}$ are in opposition.

Finally, the phase voltage equation with first harmonic hypothesis for each virtual machine (with considering only the first and third time and space harmonic for the five-phase machine) is expressed from (7) and (8):

$$
v\left(\theta_{e}\right)=v_{1}\left(\theta_{e}\right)+v_{3}\left(\theta_{e}\right)
$$

\section{Torque and power expressions}

MM torque $t_{1}$ (in p.u.) and SM torque $t_{3}$ (in p.u.) can be calculated from (7) and (8):

$$
\left\{\begin{aligned}
t_{1} & =i_{1} \cos \theta_{1} \\
t_{3} & =\frac{e_{3}}{e_{1}} i_{3} \cos \theta_{3}
\end{aligned}\right.
$$

The total electromagnetic torque of the five-phase machine is the sum of the torque provided by each virtual machine:

$$
t=t_{1}+t_{3}
$$

The electromagnetic powers $p_{e m, 1}$ and $p_{e m, 3}$ of the MM and SM are also obtained:

$$
\left\{\begin{array}{l}
p_{e m, 1}=e_{1} y i_{1} \cos \theta_{1} \\
p_{e m, 3}=e_{3} y i_{3} \cos \theta_{3}
\end{array}\right.
$$

\section{TORQUE AND POWER VS SPEED CHARACTERISTICS}

\section{A. Optimization problem}

For a given speed $y$, taking into account the maximum DC voltage (driven by base voltage $V_{b}$ ) and the maximum copper losses (driven by base current $I_{b}$ ), the goal consists in finding the MM and SM current distribution that maximizes the electromagnetic torque. To solve this problem is equivalent to find the optimal d-axis and q-axis references for each virtual machine. The optimization variable is defined as follows:

$$
z=\left[\begin{array}{llll}
i_{1} & \theta_{1} & i_{3} & \theta_{3}
\end{array}\right]^{T}
$$

The optimization variable is lower and upper bounded according to the following relations:

$$
Z_{\text {low }}=\left[\begin{array}{c}
0 \\
-\pi \\
0 \\
-\pi
\end{array}\right] \leq z \leq\left[\begin{array}{l}
1 \\
\pi \\
1 \\
\pi
\end{array}\right]=Z_{u p}
$$

The objective is to maximize the electromagnetic torque. This goal is expressed in the following relation where the electromagnetic torque can be calculated considering (11):

$$
z^{*}=\arg \min (-t(z))
$$

The non linear constraint regarding the peak phase voltage is written in the following relation (where the voltage is given by (9)):

$$
f_{v}(z)=\max \left\{v\left(\theta_{e}, z\right), \theta_{e} \in[0 . .2 \pi]\right\}-v_{\text {peak }}
$$

The constraint relative to the maximum RMS current is quadratic and is defined by the following equation:

$$
f_{i}(z)=z(1)^{2}+z(3)^{2}-1
$$


The following expression summarizes the optimization problem under consideration:

$$
\begin{aligned}
& z^{*}=\quad \arg \min (-t(z)) \\
& \text { with }\left\{\begin{array}{l}
Z_{\text {low }} \leq z \leq Z_{u p} \\
f_{v}(z) \leq 0 \\
f_{i}(z) \leq 0
\end{array}\right.
\end{aligned}
$$

The choice of $v_{\text {peak }}$ greatly influences the optimization results. In this study, the peak voltage is set with considering the base voltage $V_{b}$ :

$$
v_{\text {peak }}=\frac{\max \left\{v\left(\theta_{e}\right), \theta_{e} \in[0 . .2 \pi]\right\}}{V_{b} \sqrt{2}}=1
$$

Equation (19) means that the base sinusoidal supply of the Main Machine determines the maximum allowable peak voltage (according to the base voltage definition subsequently given in subsection II-B). Actually, the optimization problem is written such as the five-phase machine never operates with a modulation signal whose magnitude does not comply with the DC bus voltage (linear modulation operation).

If the optimization problem is solved for several speeds $y$, a set of optimum points $z^{*}(y)$ is thus obtained. The torque and power versus speed characteristics are then obtained by drawing $t\left(z^{*}(y)\right)$ and $p_{e m}\left(z^{*}(y)\right)$ respectively. For instance, Fig. $2 \mathrm{a}$ and Fig. $2 \mathrm{~b}$ show respectively the optimized torque/speed and power/speed characteristics when considering a five-phase machine with $e_{3} / e_{1}=0.3$ and $x_{3} / x_{1}=0.5$. It should be noted that the considered machine has a quite low armature reaction $x_{1}$, thus making the theoretical speed range finite.

In the two figures, the blue dash lines correspond to the torque and power base characteristics: these analytically predictable curves are obtained according to sinus electromotive force and sinus current hypotheses $\left(e_{3}=i_{3}=0\right)$. The solid lines are obtained with solving optimization problem (18) for several speeds. This example illustrates how the SM affects the Torque/Speed characteristic in FW operation and allows to both increase the torque and the power for given volt-ampere ratings. Fig. 3 give another insight of how the optimization procedure works. Fig. 3a shows the found optimum current paths in both MM d1q1-plane and SM d3q3-plane. Flux weakening starts as soon as $\mathrm{d} 1$ or $\mathrm{d} 3$-axis current is not null. The dash line locates the four-dimension point $\left(i_{d 1}, i_{q 1}, i_{d 3}, i_{q 3}\right)$ where the electromagnetic power is maximum. Fig. $3 \mathrm{~b}$ gives the corresponding phase voltage: one can observe that the voltage constraint is saturated since the peak value of the phase voltage equals one.

To better assess the change due to SM properties on the torque, power and speed range, it is useful to extract from the torque and power curves three singular points: the maximum torque point, the maximum power point and the maximum speed point.

\section{B. Maximum torque point}

Actually, below the base speed, the virtual machine torque sharing and the resulting maximum torque $t_{m}$ depends on

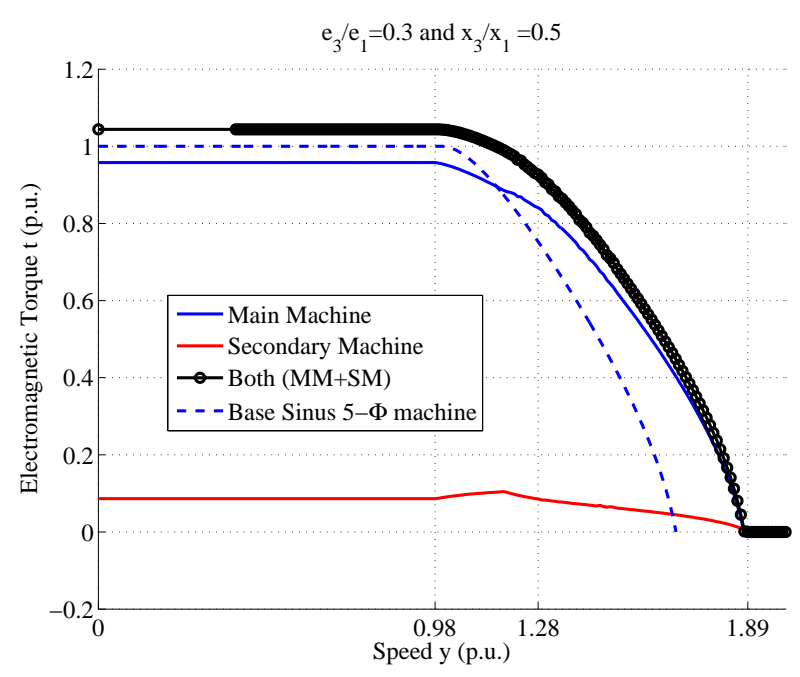

(a) Torque

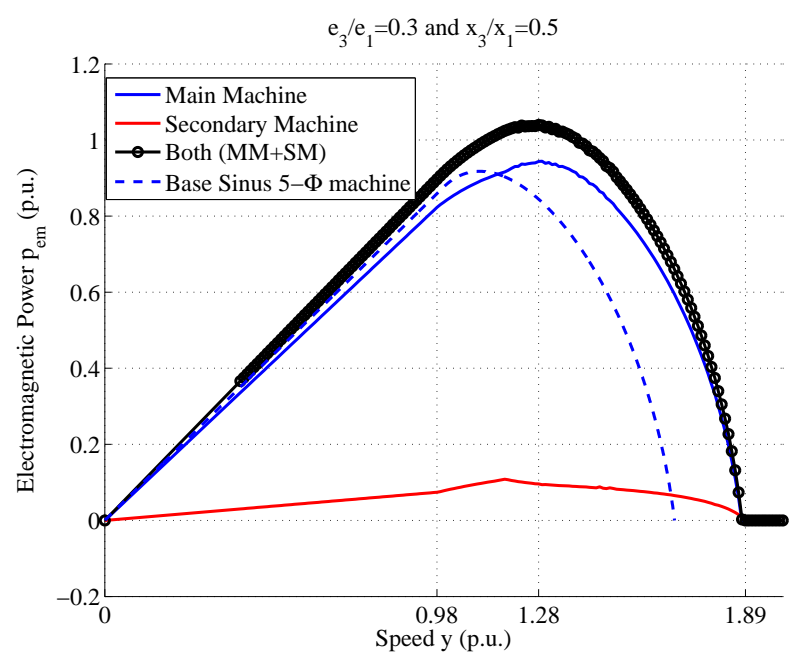

(b) Power

Fig. 2. Electromagnetic torque and power versus speed characteristics $\left(x_{1}=\right.$ 0.28 and $r=0.08$ )

$e_{3} / e_{1}$ ratio and can be analytically estimated [17]:

$$
\left\{\begin{array}{l}
\left(i_{1}, \theta_{1}\right)=\left(\frac{e_{1}}{\sqrt{e_{1}^{2}+e_{3}^{2}}}, 0\right) \\
\left(i_{3}, \theta_{3}\right)=\left(\frac{e_{3}}{\sqrt{e_{1}^{2}+e_{3}^{2}}}, 0\right)
\end{array} \Rightarrow t_{m}=\sqrt{1+\left(\frac{e_{3}}{e_{1}}\right)^{2}}\right.
$$

However, the highest speed where this maximum torque $t_{m}$ (equal to 1.04 in the example of Fig. 2) can be maintained depends on the non linear constraint on the peak voltage: the optimization procedure previously described allow to estimate this particular speed (equal to 0.98 in the example). The definition of the maximum torque can be written as follows:

$$
\left\{\begin{array}{l}
t_{m}=\max \left\{t\left(z^{*}(y)\right), y>0\right\} \\
y_{t}=\arg \max \left\{t\left(z^{*}(y)\right), y>0\right\}
\end{array}\right.
$$

If a five-phase machine with sinus back-emf $\left(e_{3}=0\right)$ and sinus current $\left(i_{3}=0\right)$ is considered, both $t_{m}$ and $y_{t}$ equal one by definition of the base point. In any case, as previously mentioned, maximum torque $t_{m}$ is analytically estimated according to (20) but $y_{t}$ can not be analytically calculated. 


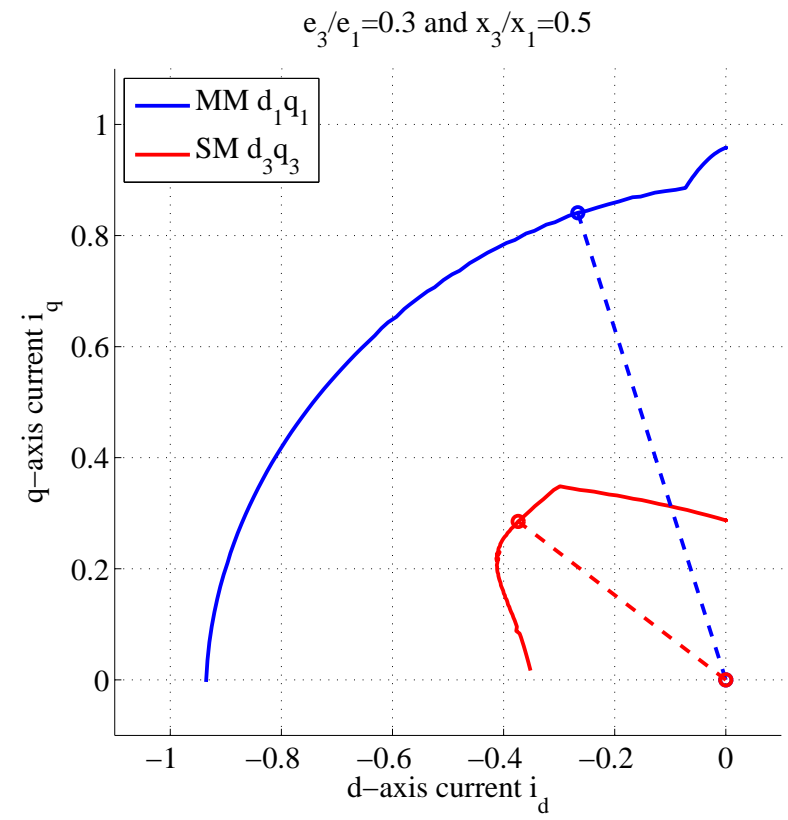

(a) MM and SM optimum current paths

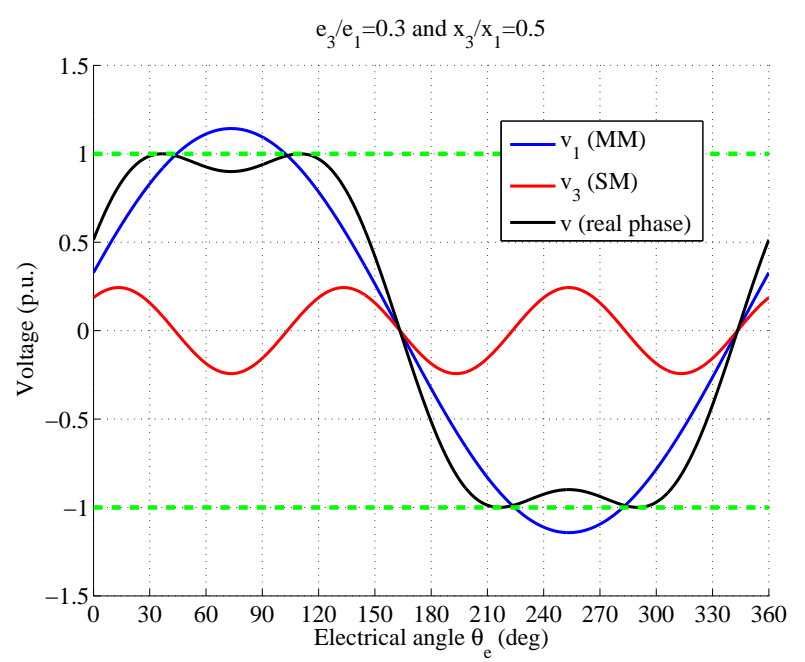

(b) Resulting phase voltage at the maximum electromagnetic power point

Fig. 3. Optimum current path in the two dq-planes and phase voltage example

\section{Maximum power point}

Another particular point corresponds to the speed where the maximum electromagnetic power is attained. This point can be defined by the following relation:

$$
\left\{\begin{array}{l}
p_{e m, m}=\max \left\{p_{e m}\left(z^{*}(y)\right), y>0\right\} \\
y_{p}=\arg \max \left\{p_{e m}\left(z^{*}(y)\right), y>0\right\}
\end{array}\right.
$$

If a five-phase machine with sinus back-emf and current ( $e_{3}=i_{3}=0$ ) is considered, $p_{m}$ and $y_{m}$ can be analytically calculated:

$$
e_{3}=i_{3}=0 \Rightarrow\left\{\begin{array}{l}
y_{p}=\frac{1-r}{\sqrt{e_{1}^{2}-x_{1}^{2}}} \\
p_{e m, m}=1-r
\end{array}\right.
$$

In the general case, a numerical approach is necessary to calculate $y_{p}$ and $p_{e m, n}$. If the example in Fig. $2 \mathrm{~b}$ is considered, one can observe that $y_{p}$ equals 1.28 (against 1.11 under sinus back-emf and current hypothesis, see (23)) and $p_{e m, n}$ equals 1.04 (against 0.92 under sinus back-emf and current hypothesis, see (23)). It should be noted that, when the third harmonic of back-emf is used, the electromagnetic power can exceed one. This observation is consistent with the definition of the base power that is obtained when the voltage and current are in-phase sinus signals with amplitudes equal to the base quantities (see (6)). According to this definition, the theoretical maximum reachable power is the one obtained when voltage and current are both squarewave with amplitudes equal to the base quantities: in this case, the electric power equals 2 (and the corresponding electromagnetic power is lower than $2-r$ ).

\section{Maximum speed point}

The last particular point corresponds to the theoretical maximum reachable speed. This speed can be defined as follows:

$$
y_{m}=\arg \left\{t\left(z^{*}(y)\right)=0, y>0\right\}
$$

If a five-phase machine with sinus back-emf $\left(e_{3}=0\right)$ and sinus current $\left(i_{3}=0\right)$ is considered, again an analytical calculation is possible:

$$
e_{3}=i_{3}=0 \Rightarrow y_{m}=\frac{\sqrt{1-r^{2}}}{e_{1}-x_{1}}
$$

For the example of Fig. 2, with sinus hypothesis, the analytically predictable maximum reachable speed is 1.68 (according to (25)) whereas, by considering the optimization problem (18), the maximum reachable speed equals 1.89 . This example illustrates how the SM affects the Torque/Speed characteristic in FW operation. However the observed results are not applicable to any five-phase machine. In the following part, a procedure to obtain general results is detailed.

\section{INFLUENCE OF THE FIVE-PHASE MACHINE PARAMETERS ON THE TORQUE/SPEED CHARACTERISTIC}

\section{A. Objectives}

The optimization problem can be solved for a set of 5phase SPM machine with the same base values (same base voltage $V_{b}$, base current $I_{b}$, base mechanical speed $\Omega_{b}$ and base torque $T_{b}$ ), thus meaning that the Main Machine inductance $x_{1}$ and back-emf $e_{1}$ are invariant (according to the definition of base point given in subsection II-B). Therefore, the optimized torque/speed characteristic only depends on the Secondary Machine inductance $x_{3}$ and flux $e_{3}$. The influence of the SM parameters on the torque/speed characteristic can then be studied just by varying the ratio between $x_{3}$ and $x_{1}$ and the ratio between $e_{3}$ and $e_{1}$, respectively called inductance ratio and back-emf ratio.

Such an approach means that it is possible to design a machine where the inductance ratio $x_{3} / x_{1}$ and the backemf ratio $e_{3} / e_{1}$ are not correlated. The inductance ratio is mainly determined by the winding distribution and the slot shape whereas the no load back-emf mainly depends on the winding distribution and magnet layer properties (magnet shape, magnetization orientation): for a given winding, it is 
then theoretically possible to design a magnet layer to obtain the wanted back-emf ratio [18]-[20].

One must bear in mind that, when changing back-emf and inductance ratios, base torque $T_{b}$, base current $I_{b}$ and base speed $\omega_{b}$ do not change: these three base quantities are defined for the common sinus control of the 5-phase machine which, according to the multimachine approach, means that only the Main Machine contributes to the torque.

The main objective is then to help the designer to predict the influence of the back-emf third harmonic term on the performance of the machine when the inverter is rated by considering the Main Machine (first space and time harmonic hypothesis). To reach this goal, the modifications on the three particular speed points due to the back-emf ratio have to be computed. Nevertheless, these results will depend on the inductance ratio of course, but also of the armature reaction value defined for the Main Machine $x_{1}$. Therefore, to correctly assess the torque and power speed characteristics change, the optimization problem has to be solved for a set of inductance ratio $x_{3} / x_{1}$ and for a set of inductance $x_{1}$. With this procedure, general trends can be obtained. Practically, for each particular speed $\left(y_{t}, y_{p}\right.$ and $\left.y_{m}\right)$, it is better (less time computing) to directly track the particular speed with an adapted optimization problem (formulated from definitions (21), (22) and (24)).

\section{B. Results}

Regarding the inductance ratio, three cases are studied:

- a case where the inductance ratio is low $\left(x_{3} / x_{1}=0.5\right)$; such a ratio can be obtained in case of full pole-pitch integral-slot winding [23]

- a case where the inductance ratio is medium $\left(x_{3} / x_{1}=1\right)$; such a ratio can be obtained in case of tooth-pitch winding (which can be achieved with integral-slot or fractionalslot distribution)

- a case where the inductance ratio is high $\left(x_{3} / x_{1}=1.5\right)$; such a ratio is possibly obtained for particular 5-phase machines [24], [25].

To illustrate how the design can impact the inductance ratio value, Fig. 4 shows two five-phase integral-slot winding distributions: the full pole-pitch coils configuration in Fig. 4 a can provide a low inductance ratio (if the stator leakage inductance is large enough) whereas the tooth-pitch coils configuration in Fig. $4 \mathrm{~b}$ allows to obtain a medium inductance ratio.

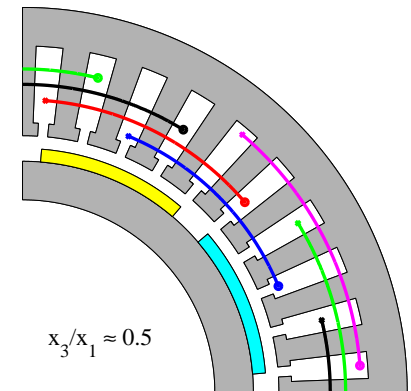

(a) Full-pole pitch winding

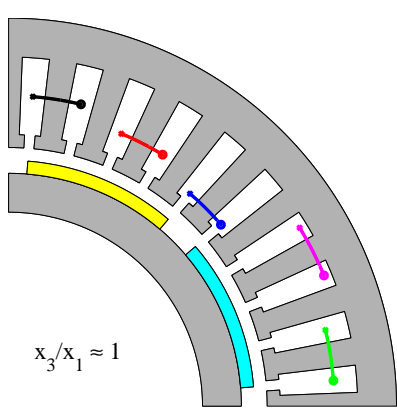

(b) Tooth-pole pitch winding
Fig. 4. Winding distribution effect on the inductance ratio
For a machine with armature reaction $x_{1}=0.28$ (and resistance $r=0.08$ ), the optimization results obtained for the three mentioned inductance ratios are reported in Fig. 5-a, -b and -c respectively. Each figure shows the maximum torque speed $y_{t}$, the maximum power speed $y_{p}$ and the maximum reachable speed $y_{m}$ changes according to the back-emf ratio $e_{3} / e_{1}$. The dash lines correspond to the maximum torque (analytical law given by (20)) and the maximum electromagnetic power.

For every simulated case, the following observation can be done: the larger the back-emf ratio $\left|e_{3} / e_{1}\right|$ is,

- the lower the maximum torque speed $y_{t}$, maximum power speed $y_{p}$ and maximum reachable speed $y_{m}$ are

- the higher the maximum torque $t_{m}$ is (as analytically predictable, see (20))

- the lower the maximum electromagnetic power $p_{e m, m}$ is.

It can be concluded that the speed range and the Volt-Ampere inverter use are reduced, thus meaning that the inverter adaptation to the machine is adversely affected. By contrast high back-emf ratio $e_{3} / e_{1}$ (it will be the case for the machine studied in section V) can facilitate the increase of torque at low speed when this feature is required (in hybrid vehicle for instance).

Nevertheless, when the inductance ratio $x_{3} / x_{1}$ increases, the reduction of $y_{t}, y_{p}, y_{m}$ and $p_{e m, m}$ (referring to their values near to $e_{3} / e_{1}=0$ ) occurs as from higher values of $\left|e_{3} / e_{1}\right|$. For example, in Fig. 5-a where inductance ratio equals $0.5, y_{p}$ is almost invariant (about 1.3) for back-emf ratio between -0.2 and 0.25 whereas, in Fig. 5-c where inductance ratio equals $1.5, y_{p}$ is almost unaffected by the back-emf ratio. Actually, the speed range and the maximum power are less affected by the magnitude of third harmonic back-emf. One can deduce that the inverter tolerates more easily the third harmonic if the inductance ratio $x_{3} / x_{1}$ is large. In this case, the SM facilitates the FW operation. Practically, it is possible to use the third harmonic without oversizing the inverter.

This trend is even truer when the base armature reaction $x_{1}$ is higher. Fig. 6 summarizes the results obtained for machines with $x_{1}=0.5$ and $r=0.05$. The rises in the maximum reachable speed $y_{m}$ in Fig. 6-a, Fig. 6-b and Fig. 6-c with reference to Fig. 5-a, Fig. 5-b and Fig. 5-c are due to the base armature reaction increase ( $x_{1}$ goes from 0.28 to 0.5 ) as for three-phase machines [3]. If we focus on Fig. 6-c that deals with the case of high inductance ratio $x_{3} / x_{1}=1.5$, maximum power speed $y_{p}$, maximum power $p_{e m, m}$ and maximum reachable speed $y_{m}$ are almost invariant (insensitive to $e_{3} / e_{1}$ ratio). This property can be seen as a better capacity of the inverter to work with the third harmonic. Practically, the designer can imagine a machine where the back-emf third harmonic term equals the back-emf fundamental $e_{3} / e_{1}=1$ : without oversizing the inverter (referring to a first space and time harmonic rating), it is possible to maintain the speed range and the maximum power whereas the maximum torque is increased. The adverse effect is a reduction of the speed of maximum torque $y_{t}$. This can be tolerated for applications where the maximum is required at low speed. 


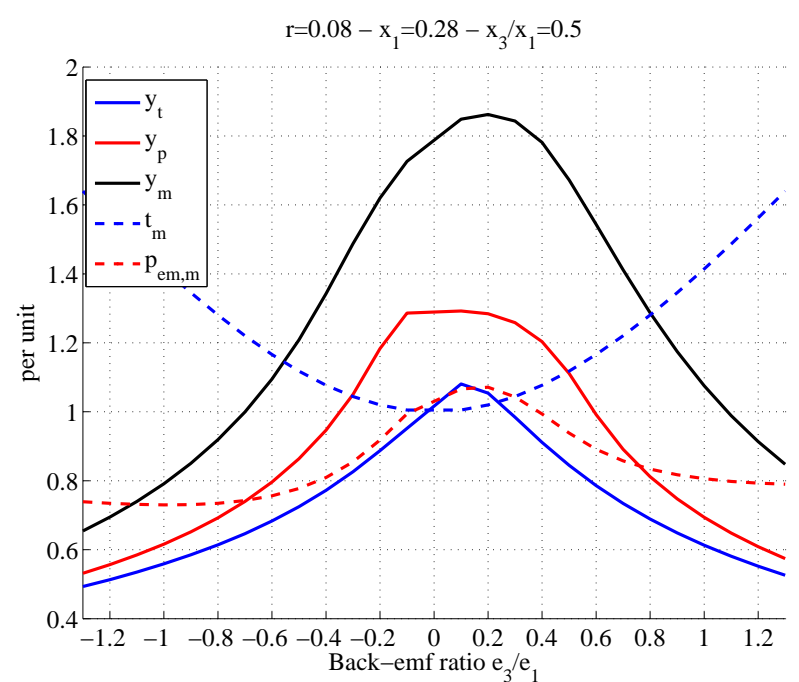

(a) Low inductance ratio: $x_{3} / x_{1}=0.5$

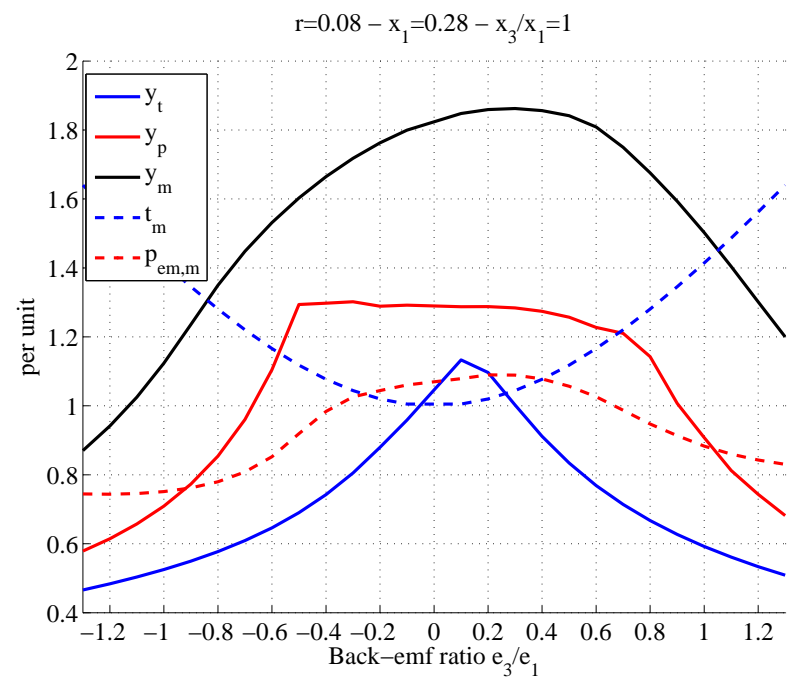

(b) Medium inductance ratio: $x_{3} / x_{1}=1$

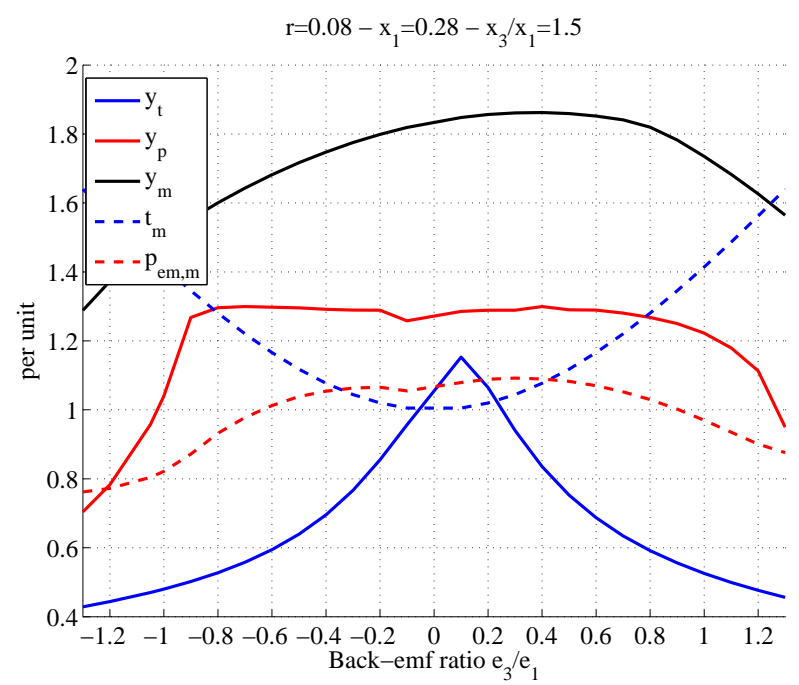

(c) High inductance ratio: $x_{3} / x_{1}=1.5$

Fig. 5. Particular speeds, maximum torque and maximum em power change with $e_{3} / e_{1}$ for machine with $x_{1}=0.28$ and $r=0.08$

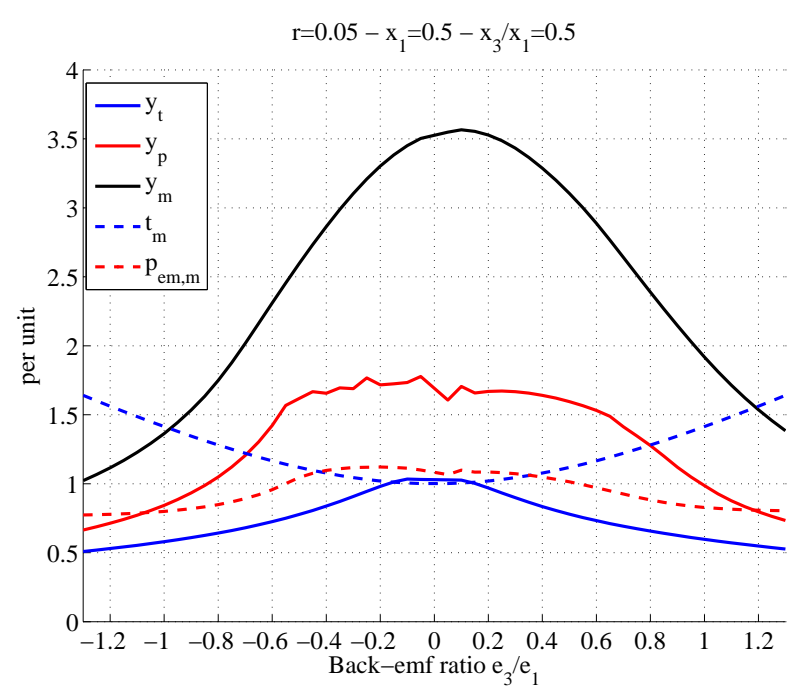

(a) Low inductance ratio: $x_{3} / x_{1}=0.5$

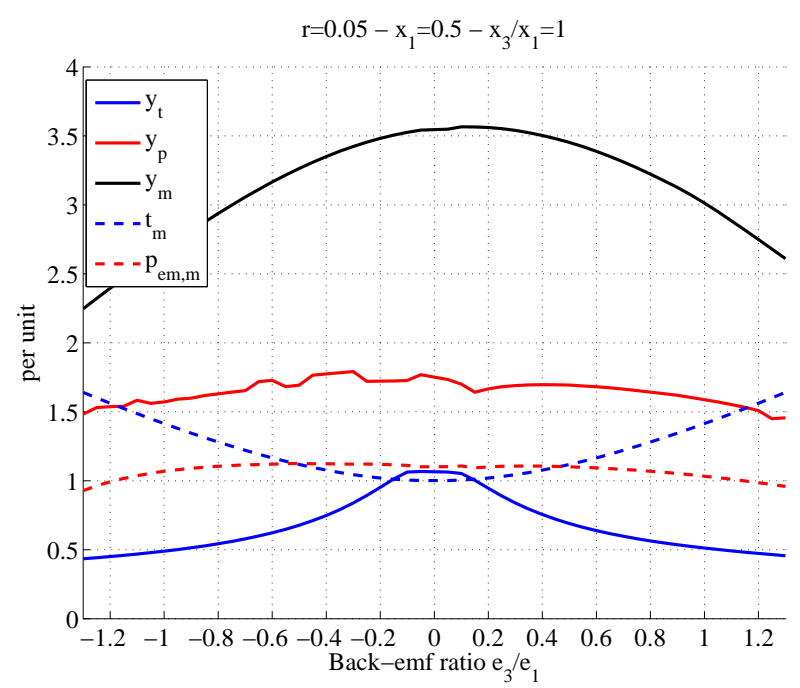

(b) Low inductance ratio: $x_{3} / x_{1}=1$

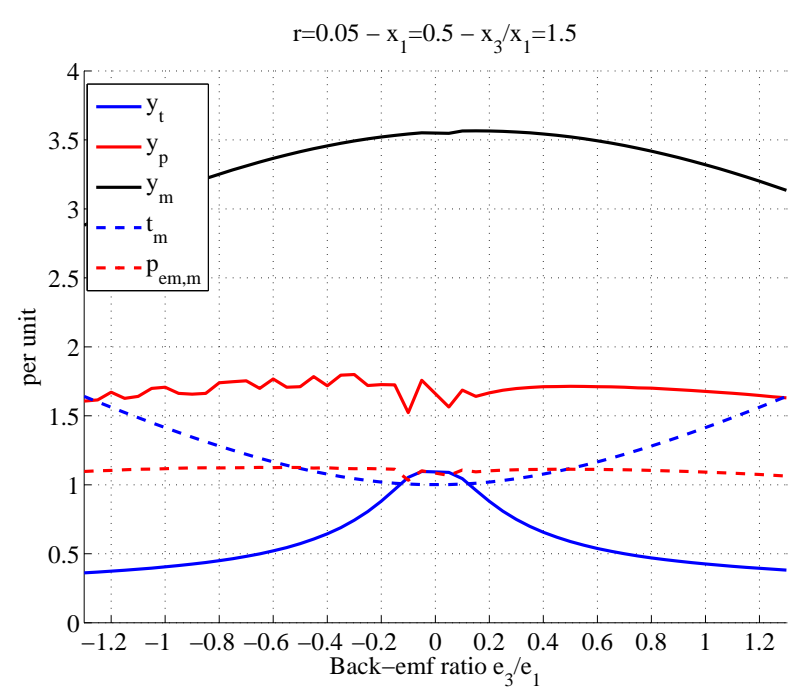

(c) High inductance ratio: $x_{3} / x_{1}=1.5$

Fig. 6. Particular speeds, maximum torque and maximum em power change with $e_{3} / e_{1}$ for machine with $x_{1}=0.50$ and $r=0.05$ 


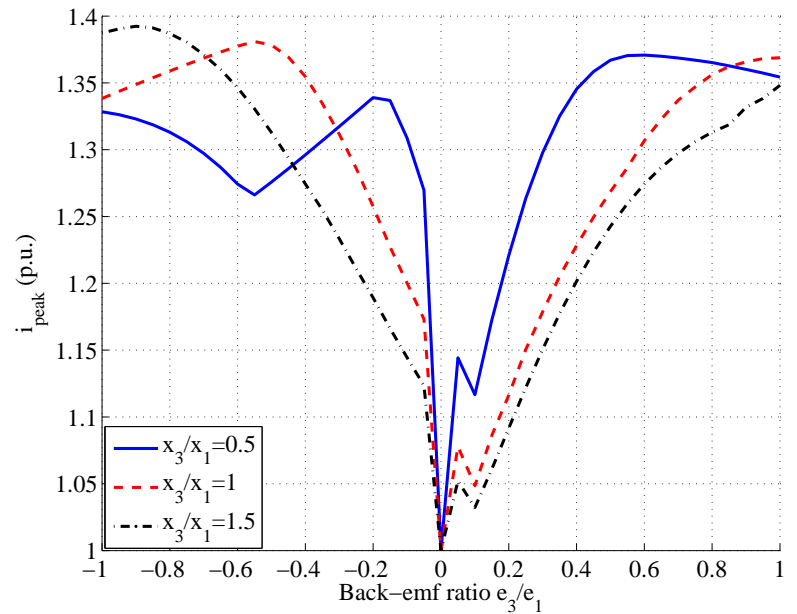

(a) $x_{1}=0.28$ and $r=0.08$

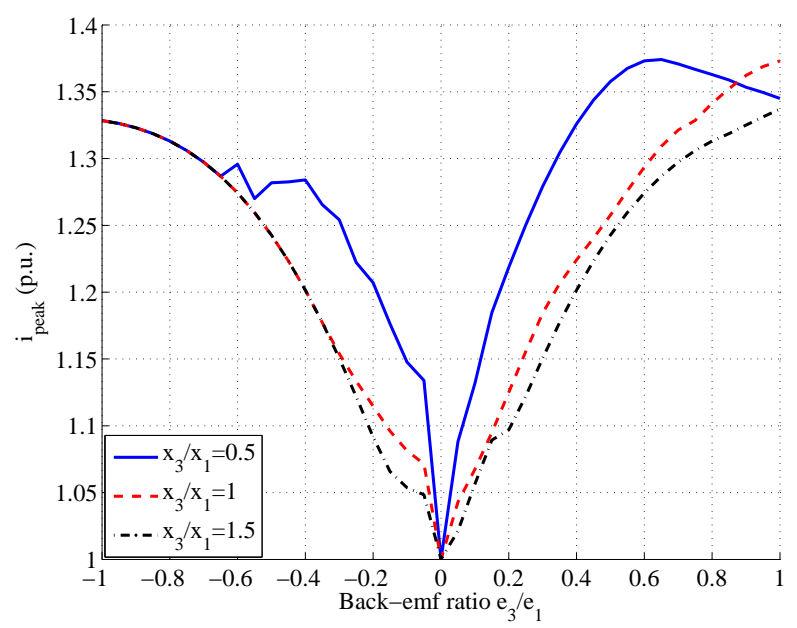

(b) $x_{1}=0.5$ and $r=0.05$

Fig. 7. Maximum peak current $i_{\text {peak }}$ according to $e_{3} / e_{1}$

\section{Peak current estimation}

The considered optimization problem (see (18)) constrains the RMS current (that drives the copper losses) but not the peak current whereas this value is a key parameter to size the inverter. By analyzing each optimal torque/speed characteristic $t\left(z^{*}(y)\right)$ (each computed $\left(e_{3} / e_{1}, x_{3} / x_{1}\right)$ point, done for $x_{1}=0.28$ and $\left.x_{1}=0.5\right)$, the maximum peak current change according to the back-emf ratio obtained for the three inductance ratios can be drawn. The results, reported in Fig. $7 \mathrm{a}$ for $x_{1}=0.28$ in Fig. $7 \mathrm{~b}$ for $x_{1}=0.5$, show that the peak current is never higher than 1.4 time the peak base current, which is acceptable.

\section{CAse Study}

In this part, we aim to show how the method and results previously described can be used to predict the Torque/Speed characteristic of a five-phase machine at the design step. According to results given in section IV-B, a five-phase machine with high back-emf third harmonic and with MM inductance large enough $\left(x_{1} \approx 0.5\right)$ owns a significant speed range when the VA inverter is sized under sinus back-emf and current assumption. Such a machine is hereafter designed.

\section{A. Machine design}

To obtain a 5-phase machine with significant torque ability for the $\operatorname{SM}\left(\left|e_{3} / e_{1}\right| \approx 1\right.$ and $\left.x_{3}>x_{1}\right)$, a particular fractionalslot winding is selected [24], [25]. Furthermore the electromagnetic circuit is designed to increase the cyclic inductance value. By using an analytical procedure close to the one described in [19], the magnet layer shape is optimized to obtain the required back-emf: fundamental and third harmonic amplitudes almost equal $\left(\left|e_{1}\right| \approx\left|e_{3}\right|\right)$ and very low amplitudes for the other harmonic terms. The resulting machine is depicted in Fig. 8 where the winding distribution and the optimal trapezoid magnet shapes can be observed. The pole is made with two identical trapezoid magnets whose shape represented by parameter $s$ (as illustrated by Fig. 8) is optimized according to the following problem (where $e_{h}$ is the h-order harmonic term of the back-emf):

$$
\begin{aligned}
& s^{*}=\arg \min \left(e_{7}(s)^{2}+e_{9}(s)^{2}+e_{11}(s)^{2}++e_{13}(s)^{2}\right) \\
& \qquad \begin{array}{l}
0 \leq s(1) \leq 90 \\
0 \leq s(2) \leq 90 \\
0.2 h_{m} \leq s(3) \leq h_{m} \\
s(2) \leq s(1) \\
e_{\text {min }}-e_{1}(s) \leq 0 \\
0.8 e_{1}(s)-e_{3}(s) \leq 0 \\
e_{3}(s)-1.2 e_{1}(s) \leq 0
\end{array}
\end{aligned}
$$

In (26), $h_{m}$ is the radial magnet thickness (in the center of the magnet) and $e_{\min }$ is a parameter that ensures a sufficient amplitude for the MM no load back-emf. It should be noted that solutions with rectangular magnets do not allow to adequately satisfy the back-emf spectrum objective [25].

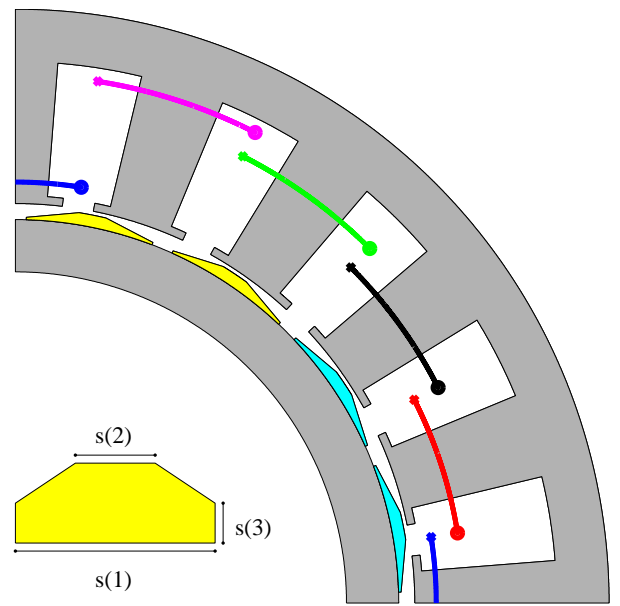

Fig. 8. Electromagnetic circuit and magnet shape parameters

The main machine parameters are listed in table I. It can be noted that the MM and SM inductances are really close: as targeted, the MM inductance is high enough $\left(x_{1}=0.56\right)$ and the SM inductance is slightly higher: $x_{3} / x_{1}=1.25$. The same conclusion can be drawn regarding the MM and SM back-emfs: $e_{1}=0.76$ and $e_{3} / e_{1}=-1.13$.

\section{B. Torque/Speed analysis}

According to section IV-B, the set of p.u. parameters for the machine under consideration suggests to refer to Fig. 6-c 
TABLE I

PARAMETERS FOR THE CONSIDERED MACHINE

\begin{tabular}{|c|c|}
\hline Base Em power & $P_{e m}=2.5 \mathrm{~kW}(0.76 p . u)$. \\
\hline Base speed & $\Omega_{b}=1000 \mathrm{rpm}(1 p . u)$. \\
\hline VA rating & $S_{b}=3.3 \mathrm{kVA}(1 p . u)$. \\
\hline Base voltage & $V_{b}=10.3 \mathrm{~V}$ \\
\hline Base current & $I_{b}=64.1 \mathrm{~A}$ \\
\hline MM back-emf & $e_{1}=0.76 p . u$. \\
\hline MM inductance & $x_{1}=0.56 p . u$. \\
\hline SM back-emf & $e_{3}=-0.86 p . u$. \\
\hline SM inductance & $x_{3}=0.70 p . u$. \\
\hline Armature resistance & $r=0.07 p . u$. \\
\hline
\end{tabular}

to determine the particular speed points: maximum speed for maximum torque $y_{t}$ is about 0.4 , maximum power point is $\left(y_{p}, p_{e m, m}\right) \approx(1.7,1.1)$ and the maximum reachable speed $y_{m}$ is about 3.1. The torque/speed characteristic is more precisely calculated with the method introduced in section III-A. Fig. 9 shows the resulting curves. It can be noted that the maximum power is $p_{e m}=0.90$ (at $y_{p}=1.77$ speed) whereas the base power is $e_{1}=0.76$ that corresponds to $2.5 \mathrm{~kW}$ (according to table I). Therefore the real maximum power (at $y_{p}$ speed) is almost 3.0kW. Finally the found particular speed points obtained by FEA analysis (FEMM software, [26]) are close to the ones predicted according to Fig. 6-c. With FEA, it is possible to verify that the assumptions of the study are acceptable: in Fig. 10, it can be observed that the saturation does not occur at the maximum power point and that the magnets are not subjected to demagnetization hazard. The values of required voltage and delivered torques have been also verified by FEA (the phase voltages are estimated by adding the phase flux time derivatives with the armature resistance voltages)

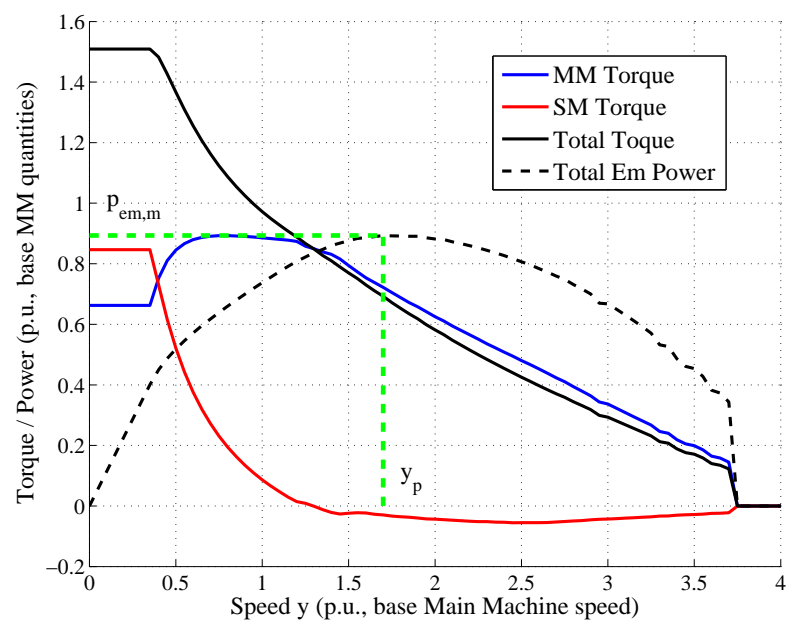

Fig. 9. Torque and power versus speed characteristic for the studied machine

\section{CONCLUSION}

In this paper, the study of torque/speed and power/speed characteristics for five-phase SPM machine is carried out.

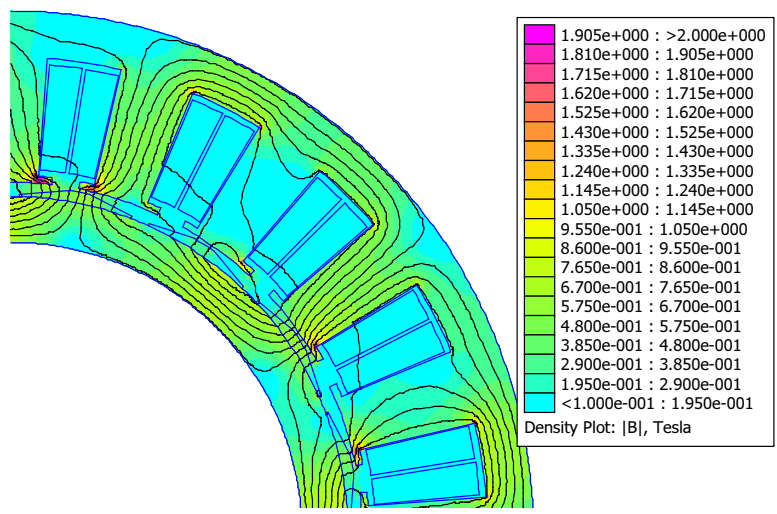

Fig. 10. Flux density at the maximum power point (FEA, [26])

This analysis is achieved with considering several hypotheses: linear magnetic modeling, star-connected machine, low armature reaction, back-emf and machine currents only contain first and third harmonic terms. For Volt-Ampere inverter rated with only considering the first harmonic of back-emf and current (the virtual MM), an optimization problem that aims to maximize the torque for given maximum peak voltage and RMS current at a given speed is formulated. This problem is solved for several back-emf and inductance ratios. To facilitate the analysis of the results, the two virtual machine electrical quantities are converted into per unit.

The following conclusion can be drawn. The speed range and the maximum electromagnetic power are almost unaffected by the back-emf ratio if the inductance ratio is sufficiently large, thus meaning that, for given Volt-Ampere rating, the machine can produce higher torque without reducing its speed range. The capability of the inverter to work is improved when injecting third harmonic. This property is all the truer as the base armature reaction is large. These results are confirmed by the numerical simulation of a particular five-phase machine with significant base armature reaction $\left(x_{1}=0.56\right)$ and large inductance ratio $\left(x_{3} / x_{1}=1.25\right)$ : at low speed, the torque can reach 1.45 times the base torque. More generally, for a five-phase Permanent Magnet machine supplied with limited Volt-Ampere, the paper shows that the impact of the third space harmonic must be taken into account when designing the winding and the PM rotor.

Further studies should be done to fully assess the here claimed property concerning the speed range. For instance, in this study, the real time control is not taken into account and it is well known that flux weakening mode is not easy to operate because both machine and converter work near their limits. Another point to analyze is the drive efficiency: copper, iron and magnet losses has to be estimated to determine the optimum virtual machine torque distribution in partial loads [25]. Further works should also address PM machines with saliency (where d-axis and q-axis inductances are not equal) since these machines are appreciated when a large flux weakening region is required.

\section{REFERENCES}

[1] L. Lu, B. Aslan, L. Kobylanski, P. Sandulescu, F. Meinguet, X. Kestelyn, and E. Semail, "Computation of optimal current references for flux- 
weakening of multi-phase synchronous machines," in IECON 2012 38th Annual Conference on IEEE Industrial Electronics Society, Oct 2012, pp. 3610-3615.

[2] R. Schiferl and T. Lipo, "Power capability of salient pole permanent magnet synchronous motors in variable speed drive applications," in Industry Applications Society Annual Meeting, 1988., Conference Record of the 1988 IEEE, Oct 1988, pp. 23-31 vol.1.

[3] W. Soong and T. Miller, "Field-weakening performance of brushless synchronous ac motor drives," Electric Power Applications, IEE Proceedings -, vol. 141, no. 6, pp. 331-340, Nov 1994.

[4] F. Magnussen, P. Thelin, and C. Sadarangani, "Performance evaluation of permanent magnet synchronous machines with concentrated and distributed windings including the effect of field-weakening," in Power Electronics, Machines and Drives, 2004. (PEMD 2004). Second International Conference on (Conf. Publ. No. 498), vol. 2, March 2004, pp. 679-685 Vol.2.

[5] A. M. El-Refaie, T. M. Jahns, and D. W. Novotny, "Analysis of surface permanent magnet machines with fractional-slot concentrated windings," IEEE Transactions on Energy conversion, vol. 21, no. 1, pp. 34-43, March 2006.

[6] P. Sandulescu, F. Meinguet, X. Kestelyn, E. Semail, and A. Bruyere, "Flux-weakening operation of open-end winding drive integrating a costeffective high-power charger," Electrical Systems in Transportation, IET, vol. 3, no. 1, pp. 10-21, March 2013.

[7] — , "Control strategies for open-end winding drives operating in the flux-weakening region," Power Electronics, IEEE Transactions on, vol. 29, no. 9, pp. 4829-4842, Sept 2014.

[8] A. Bruyere, X. Kestelyn, F. Meinguet, and E. Semail, "Rotary drive system, method for controlling an inverter and associated computer program," US Patent 20140306627,10 16, 2014

[9] H.-M. Ryu, J.-H. Kim, and S.-K. Sul, "Analysis of multiphase space vector pulse-width modulation based on multiple d-q spaces concept," Power Electronics, IEEE Transactions on, vol. 20, no. 6, pp. 1364-1371, Nov 2005.

[10] L. Parsa, N. Kim, and H. Toliyat, "Field weakening operation of high torque density five-phase permanent magnet motor drives," in Electric Machines and Drives, 2005 IEEE International Conference on, May 2005, pp. 1507-1512.

[11] S. Xuelei, W. Xuhui, and C. Wei, "Research on field-weakening control of multiphase permanent magnet synchronous motor," in Electrical Machines and Systems (ICEMS), 2011 International Conference on, Aug 2011, pp. 1-5.

[12] E. Levi, D. Dujic, M. Jones, and G. Grandi, "Analytical determination of dc-bus utilization limits in multiphase vsi supplied ac drives," Energy Conversion, IEEE Transactions on, vol. 23, no. 2, pp. 433-443, June 2008.

[13] D. Casadei, D. Dujic, E. Levi, G. Serra, A. Tani, and L. Zarri, "General modulation strategy for seven-phase inverters with independent control of multiple voltage space vectors," Industrial Electronics, IEEE Transactions on, vol. 55, no. 5, pp. 1921-1932, May 2008.

[14] D. Casadei, M. Mengoni, G. Serra, A. Tani, L. Zarri, and L. Parsa, "Control of a high torque density seven-phase induction motor with field-weakening capability," in Industrial Electronics (ISIE), 2010 IEEE International Symposium on, July 2010, pp. 2147-2152.

[15] J. Gong, B. Aslan, F. Gillon, and E. Semail, "High-speed functionality optimization of five-phase PM machine using third harmonic current," COMPEL, vol. 33, no. 3, pp. 879-893, April 2014.

[16] F. Scuiller and E. Semail, "Inductances and back-emf harmonics influence on the torque/speed characteristic of five-phase spm machine," in Vehicle Power and Propulsion Conference (VPPC), 2014 IEEE, Oct 2014, pp. 1-6.

[17] X. Kestelyn and E. Semail, "A vectorial approach for generation of optimal current references for multiphase permanent-magnet synchronous machines in real time," Industrial Electronics, IEEE Transactions on, vol. 58, no. 11 , pp. $5057-5065$, nov. 2011.

[18] K. Wang, Z. Zhu, and G. Ombach, "Torque improvement of fivephase surface-mounted permanent magnet machine using third-order harmonic," Energy Conversion, IEEE Transactions on, vol. 29, no. 3, pp. 735-747, Sept 2014.

[19] F. Scuiller, "Magnet shape optimization to reduce pulsating torque for a five-phase permanent-magnet low-speed machine," Magnetics, IEEE Transactions on, vol. 50, no. 4, pp. 1-9, April 2014.

[20] F. Scuiller, E. Semail, J.-F. Charpentier, and P. Letellier, "Multi-criteria based design approach of multiphase permanent magnet low speed synchronous machines," IET Electric Power Applications, vol. 3, no. 2, pp. 102-110, 2009
[21] E. Semail, A. Bouscayrol, and J.-P. Hautier, "Vectorial formalism for analysis and design of polyphase synchronous machines," Eur. Phys. J., vol. AP 22, pp. 207-220, 2003.

[22] K. Laskaris and A. Kladas, "Optimal power utilization by adjusting torque boost and field weakening operation in permanent magnet traction motors," Energy Conversion, IEEE Transactions on, vol. 27, no. 3, pp. 615-623, Sept 2012.

[23] F. Scuiller, E. Semail, and J.-F. Charpentier, "General modeling of the windings for multi-phase ac machines. application for the analytical estimation of the mutual stator inductances for smooth air gap machines," Eur. Phys. J. Appl. Phys., vol. 50, no. 3, pp. 1-15, june 2010.

[24] B. Aslan and E. Semail, "New 5-phase concentrated winding machine with bi-harmonic rotor for automotive application," in International Congress on Electrical Machines, 2014, September 2014.

[25] H. Zahr, E. Semail, and F. Scuiller, "Five-phase version of 12slots/8poles three-phase synchronous machine for marine-propulsion," in Vehicle Power and Propulsion Conference (VPPC), 2014 IEEE, Oct 2014, pp. $1-6$.

[26] D. Meeker, "Finite element method magnetics, version 4.2, users manual," FEMM official website, October 2010

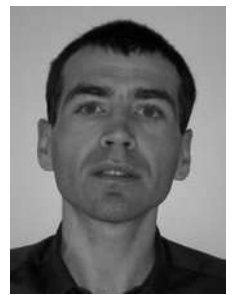

Franck Scuiller (M'11) received the Electrical Engineering degree (M.Sc. degree) from ENSIEG, INPG (Grenoble National Polytechnic Institute) in 2001 and the Ph.D. degree from Arts et Metiers ParisTech in 2006. In 2007, he was a lecturer in French Naval Academy. From 2008 to 2011, he was a technical project manager in warship electric power systems for DCNS company (Lorient, France). Since September 2011, he is an Associate Professor in Electrical Engineering in the French Naval Academy. His research interest is multi-phase machines for marine applications (ship propulsion, marine current turbine).

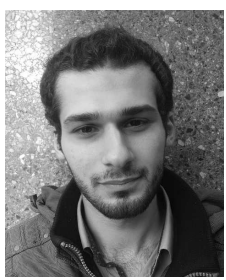

Hussein Zahr (SM'13) received the B.Sc degree in electrical engineering from Lebanese university, faculty of engineering, Beirut, Lebanon, in 2012 and received the M.S degree in electrical engineering from Ecole Polytechnique de Nantes, Nantes, France in 2013. He is currently working toward the Ph.D. degree in electical engineering at Ecole Nationale Superieure des Arts et Metiers, Lille, France. His current research interests include design, modeling and control of multi-phase machines.

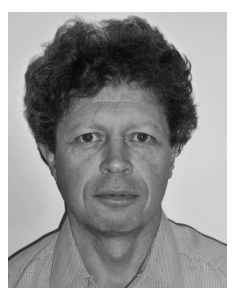

Eric Semail (M'02) is graduated in 1986 from the Ecole Normale Supérieure, in France. He received Ph.D. degree in 2000 on Tools and studying method of polyphase electrical systems, Generalization of the space vector theory. He became Associate Professor at Engineering school of ARTS et METIERS PARISTECH in 2001 and full Professor in 2010. In Laboratory of Electrical Engineering of Lille (L2EP) in France, his fields of interest include design, modeling and control of multi-phase electrical drives (converters and AC Drives). More generally, he studies, as member of the Control team of L2EP, Multi-machine and Multi-converter systems. Fault Tolerance for electromechanical conversion at variable speed is one of the applications of the research with industrial partners in fields such as automotive, marine, aerospace. Since 2000, he has collaborated to the publication of 27 scientific journals, 64 International Congresses, 5 patents and 2 chapters in books at Wiley editions. 